\title{
Extensive renal infarction following percutaneous biopsy of a small renal mass: A case report
}

\author{
Samuel Abourbih, MD; ${ }^{*}$ Saad Aldousari, MD; Fadi Brimo, MD; ${ }^{\dagger}$ Atilla Omeroglu, MD; ${ }^{\dagger}$ \\ Wassim Kassouf, MD, FRCSC
}

*Division of Urology, Department of Surgery, McGill University Health Centre, Montreal, QC; 'Department of Pathology, McGill University Health Centre, Montreal, QC

Cite as: Can Urol Assoc J 2013;7:E1 18-E120. http://dx.doi.org/10.5489/cuaj.252

\section{Abstract}

Percutaneous renal biopsy has become increasingly used particularly in patients undergoing active surveillance for small renal masses. We present a patient, who was recently diagnosed with laryngeal squamous cell carcinoma, with significant complication following biopsy of a solid renal mass. The patient was planned for nephron-sparing surgery that was converted to radical nephrectomy due to extensive renal infarction secondary to significant subcapsular hemorrhage inflicted by the biopsy.

\section{Case report}

A 78-year-old male was referred to our department for an incidental left renal mass that was found on preoperative imaging following a diagnosis of pT4 laryngeal cancer. The patient underwent a laryngectomy with curative intent and uneventful recovery. On computed tomography scan, there was a 3.9-cm exophytic enhancing solid mass on the posterior aspect of the inferior pole of the left kidney (Fig. 1 ). Given the recent diagnosis of laryngeal cancer and the patient's age, a renal biopsy was performed to identify (1) whether it was a metastatic lesion or primary lesion, and (2) if it was a primary lesion, the type and grade of malignancy versus benign neoplasm. The biopsy was performed using a 16-gauge core biopsy needle. Four passes were done and no complications were noted. Pathology revealed papillary renal cell carcinoma with Fuhrman nuclear grade 2 out of 4. After discussing the various management options, the patient opted for a partial nephrectomy.

The patient was scheduled for surgery 2 months postrenal biopsy. Via a flank incision, we identified Gerota's fascia and dissected the kidney. A large perinephric hematoma was identified that encompassed the entire kidney making it impossible to identify the renal mass. Further dissection was attempted but was not helpful. Intraoperative ultrasound was requested. Ultrasonography did not demonstrate any vascular flow throughout the entire kidney, nor could it identify the lesion within the lower pole of the left kidney. However, it did reveal a potential suspicious endophytic solid lesion in the upper pole. A decision was taken to abort the attempted partial nephrectomy and proceed for a radical nephrectomy due to the following rationale: (1) the preoperative biopsy of the lower pole mass revealed papillary renal cell carcinoma, a histology that is associated with multifocal disease, (2) another endophytic suspicious lesion was noted in the upper pole, and most importantly (3) the absence of any vascular flow on Doppler suggested complete renal infarction. The patient's postoperative course was uneventful.

On pathology, extensive infarction and hemorrhage comprised most of the kidney. Another infarcted area measuring $5 \mathrm{~cm}$ was rimmed by papillary renal cell carcinoma cells, representing organ-confined infarcted tumour. One small area of viable renal parenchyma was identified and did not show significant glomerulosclerosis nor vascular abnormalities (Fig. 2, Fig. 3a, Fig. 3b).

\section{Discussion}

Detection of incidental small renal masses is increasing worldwide due to the widespread use of noninvasive imaging techniques together with improved quality of cross-sectional imaging. ${ }^{1}$ About $15 \%$ to $20 \%$ of small renal masses are benign, and most of those that are malignant are associated with less aggressive tumour biology and an indolent natural history. ${ }^{2-5}$ As such, active surveillance has been increasingly adopted within the urologic community and many urologists have implemented routine renal biopsies in this patient population. This has led to the increasing frequency of percutaneous biopsy of renal masses, as it may allow better selection of renal tumors for active surveillance and minimally invasive ablative therapies especially in the elderly or medically unfit patients.

Documented complications of renal biopsies include tumour seeding along the needle tract, bleeding, arterio- 


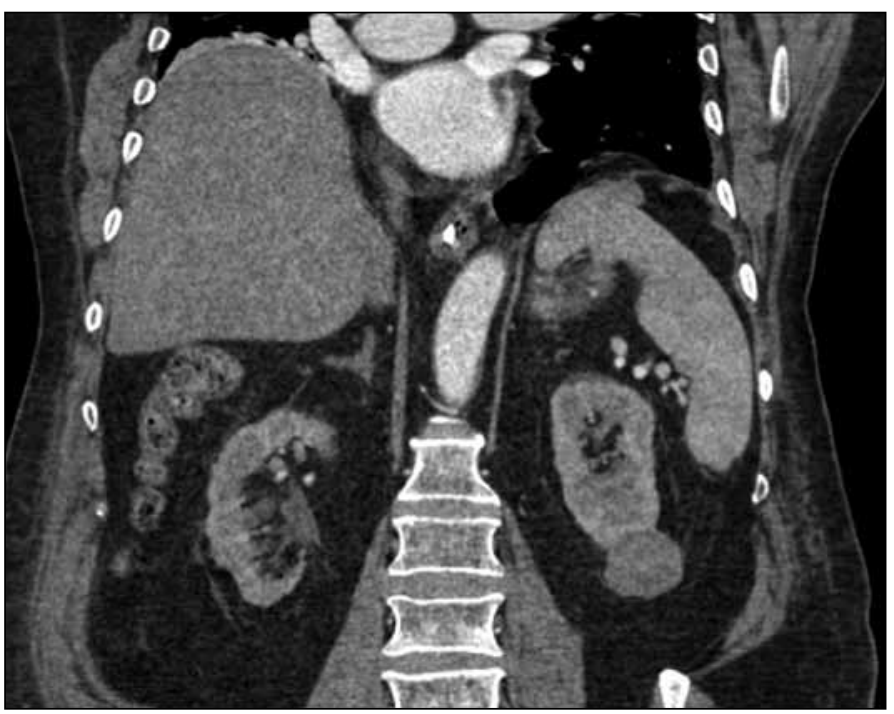

Fig. 1. Renal mass as seen on computed tomography. A 3.9-cm solid enhancing mass is located in the posterior aspect of the inferior pole of the left kidney.

venous fistula, infection and pneumothorax. The overall risk of tumour seeding along the needle tract is less than $0.01 \% .{ }^{6}$ With regards to bleeding, a recent review showed that between 2006 and 2010, there were only 4 major vascular complications out of 1083 renal mass biopsies: 3 cases of post-procedure hemorrhage requiring transfusion and 1 pseudoaneurysm requiring emobilization. ${ }^{7}$ Despite this low rate of serious complications, subcapsular hematomas are not uncommon after percutaneous biopsy, with rates as high as $40 \%$ in one series. ${ }^{8}$ Leveridge and colleagues recently published a series of 294 patients undergoing biopsy of a renal mass. ${ }^{9}$ Of those, 29 patients suffered complications almost all of which were minor (Clavien I), with only 1 patient requiring admission for gross hematuria and clot retention. The authors reported no incidences of needle tract seeding. Turna and colleagues looked at the complication

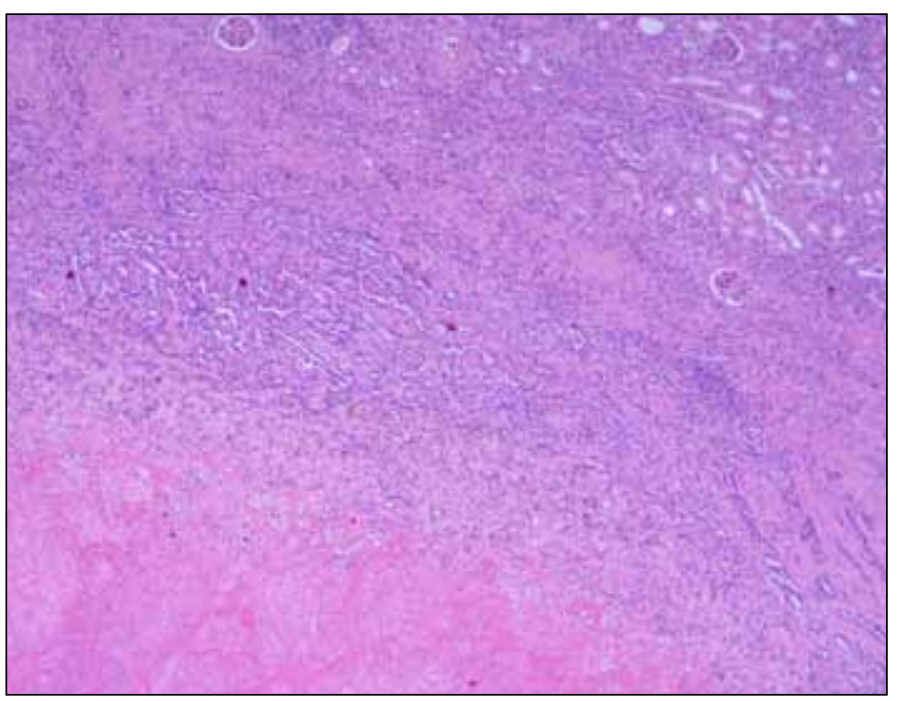

Fig. 3a. Low power magnification of infarcted papillary renal cell carcinoma.

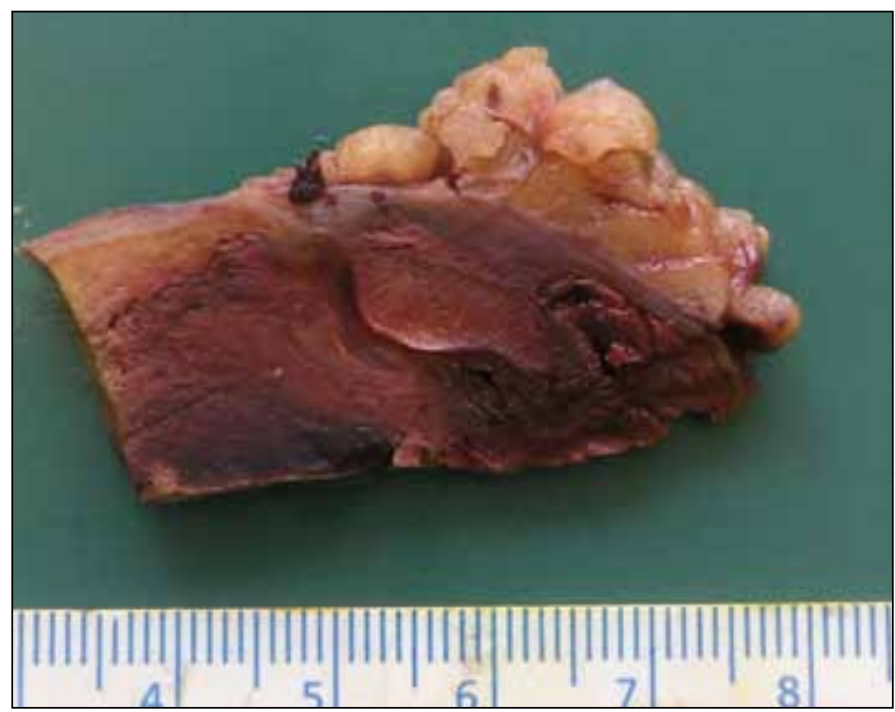

Fig. 2. Gross pathology of a representative section within the nephrectomy specimen. The kidney parenchyma is mostly replaced by hemorrhage and necrosis.

rate of laparoscopic partial nephrectomy after previous ipsilateral renal procedures, including renal biopsy and percutaneous nephrolithotomy. ${ }^{10}$ They found no intraoperative complications or conversions to open surgery and no patient required a nephrectomy.

\section{Conclusion}

Although clinically significant bleeding is unusual and almost always self-limiting in several large series, ${ }^{11,12}$ biopsy of renal masses can result in major bleeding affecting the final management of the patient, as demonstrated in our case. Due to the extensive infarction of the kidney, a radical nephrectomy was performed in a patient whose tumour

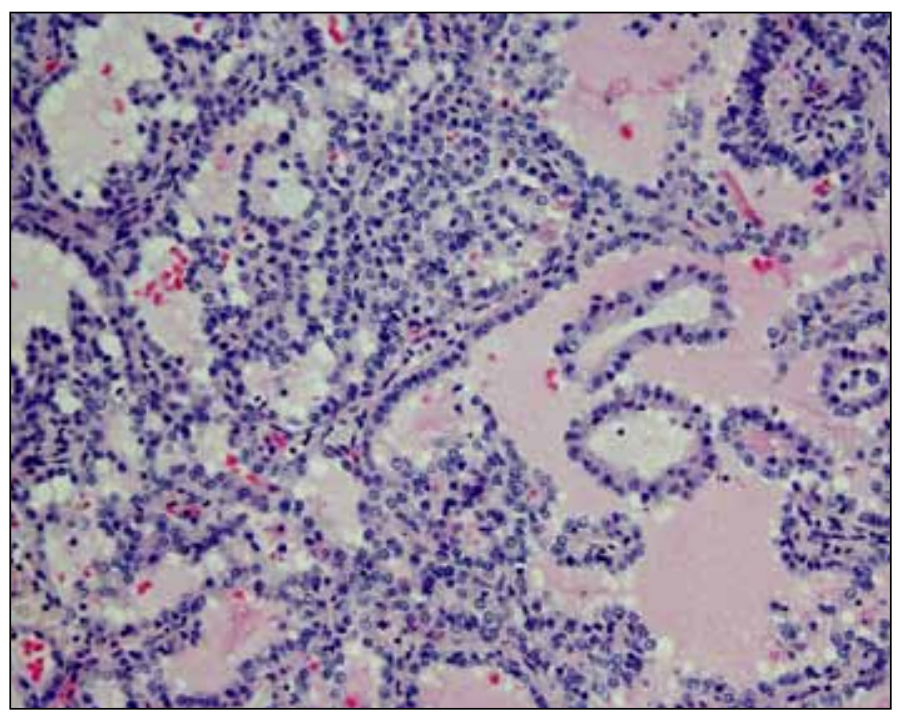

Fig. 3b. High power magnification of papillary renal cell carcinoma, Fuhrman's grade $2 / 4$. 
Abourbih et al.

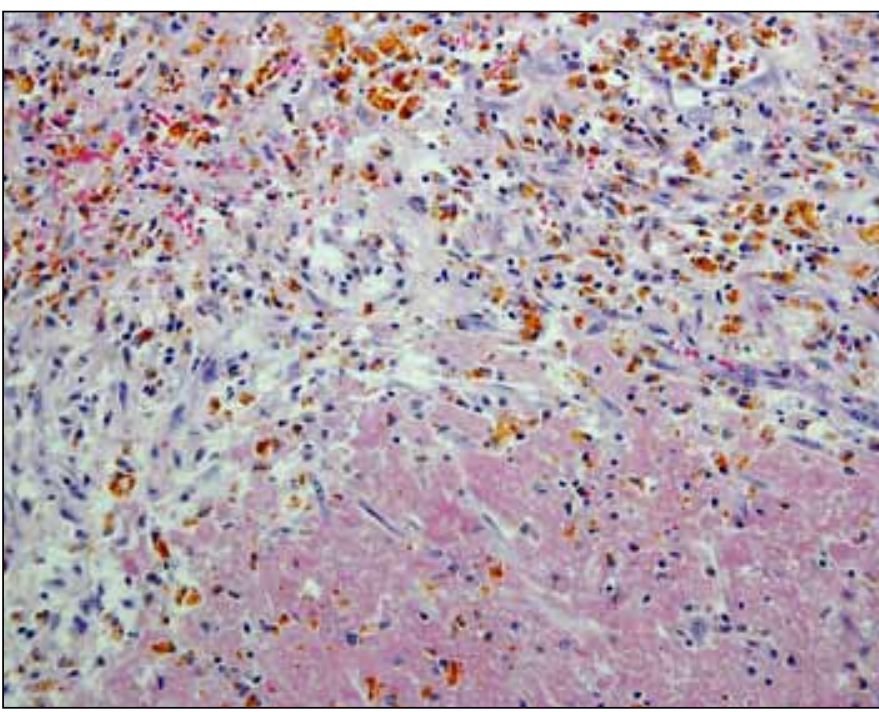

Fig. 3c. Separate areas of infarction with hemosiderin-laden macrophages, and organizing fibroblastic proliferation, of traumatic origins.

characteristics would have allowed for a relatively easy partial nephrectomy. Thus, renal mass biopsy is not without complications and care should be taken when considering it and counselling the patient.

Competing interests: None declared.

This paper has been peer-reviewed.

\section{References}

1. Chow WH, Devesa SS, Warren JL, et al. Rising incidence of renal cell cancer in the United States. JAMA 1999;281:1628-31. http://dx.doi.org/10.1001/jama.281.17.1628

2. Abou Youssif T, Kassouf W, Steinberg J, et al. Active surveillance for selected patients with renal masses: updated results with long-term follow-up. Cancer 2007;110:1010-4. http://dx.doi.org/10.1002/ cncr.22871

3. Kassouf $W$, Aprikian AG, Laplante $M$, et al. Natural history of renal masses followed expectantly. J Urol 2004;171:111-3; discussion 113. http://dx.doi.org/10.1097/01.ju.0000102409.69570.f5

4. Volpe A, Panzarella T, Rendon RA, et al. The natural history of incidentally detected small renal masses. Cancer 2004;100:738-45. http://dx.doi.org/10.1002/cncr.20025

5. Jewett MA, Mattar K, Basiuk J, et al. Active surveillance of small renal masses: progression patterns of early stage kidney cancer. Eur Urol 2011;60:39-44. http://dx.doi.org/10.1016/i.eururo.2011.03.030

6. Herts BR, Baker ME. The current role of percutaneous biopsy in the evaluation of renal masses. Semin Urol Oncol 1995; 13:254-61.

7. Samplaski MK, Zhou M, Lane BR, et al. Renal mass sampling: an enlightened perspective. Int I Urol 2011;18:5-19. http://dx.doi.org/10.1111/j.1442-2042.2010.02641.x

8. Campbell SC, Novick AC, Herts B, et al. Prospective evaluation of fine needle aspiration of small, solid renal masses: accuracy and morbidity. Urology 1997;50:25-9. http://dx.doi.org/10.1016/S00904295(97)00111-8

9. Leveridge MJ, Finelli A, Kachura JR, et al. Outcomes of small renal mass needle core biopsy, nondiagnostic percutaneous biopsy, and the role of repeat biopsy. Eur Urol 201 1;60:578-84. http://dx.doi. org/10.1016/i.eururo.2011.06.021

10. Turna $B$, Aron $M$, Frota $R$, et al. Feasibility of laparoscopic partial nephrectomy after previous ipsilateral renal procedures. Urology 2008;72:584-8. http://dx.doi.org/10.1016/j.urology.2008.04.002

11. Veltri A, Garetto I, Tosetti I, et al. Diagnostic accuracy and clinical impact of imaging-guided needle biopsy of renal masses. Retrospective analysis on 150 cases. Eur Radiol 2011;21:393-401. http://dx.doi. org/10.1007/s00330-010-1938-9. Epub 2010 Sep 1.

12. Rybicki FJ, Shu KM, Cibas ES, et al. Percutaneous biopsy of renal masses: sensitivity and negative predictive value stratified by clinical setting and size of masses. AJR Am J Roentgenol 2003;180:1281-7.

Correspondence: Dr. Wassim Kassouf, Assistant Professor of Urology, McGill University Health Centre, Montreal General Hospital, 1650 Cedar Ave. L8-315, Montreal, QC H3G 1A4; fax: 514-934-8297; wassim.kassouf@muhc.mcgill.ca 